\title{
EMPIRICAL MODEL FOR THE ESTIMATION OF GLOBAL SOLAR RADIATION IN DHAKA, BANGLADESH
}

\author{
Debazit Datta ${ }^{1}$, Bimal Kumar Datta ${ }^{2}$ \\ ${ }^{1}$ Lecturer, Department of Quantitative Sciences, International University of Business Agriculture and Technology, Dhaka, \\ Bangladesh, \\ ${ }^{2}$ Assistant Professor, Department of Mathematics, Pabna University of Science and Technology, Pabna \\ ddatta@iubat.edu,bimaldu@gmail.com
}

\begin{abstract}
This work proposes the coefficients for Angstrom-Prescott type of model for the estimation of global solar radiation in Dhaka, Bangladesh using the relative sunshine duration alongside the measured global solar radiation data (1983-2010). The model constants $a$ and $b$ obtained in this investigation for Dhaka are 0.23 and 0.57 respectively. The correlation coefficient of $87 \%$ between the clear sky index and relative sunshine duration, as well as the coefficient of determination of 75.7 obtained shows that this model fits the data very well. Consequently, the developed model in this work can be used with confidence for Dhaka and other locations with similar climate conditions.
\end{abstract}

Keywords: solar radiation, regression, extra terrestrial radiation, sunshine hours, empirical model.

\section{INTRODUCTION}

The design of a solar energy conversion system requires precise knowledge regarding the availability of global solar radiation and its components at the location of interest. An accurate knowledge of the solar radiation data for a particular location is a pre requisite, in estimating the thermal performance and economic viability of solar energy systems. Since the solar radiation reaching the earth's surface depends upon climatic conditions of the place, a study of solar radiation under local climatic conditions is essential. The availability of these data may be of the form of types of irradiance, total, diffuse, direct, surface placement and horizontal, inclined, facing south or deviated from south or in terms of time: hourly, daily, monthly or yearly. Each of these forms is important and has particular usage in specific applications.

A number of authors have proposed various empirical relationships for the estimation of daily global solar radiation on horizontal surface. Various climatologically parameters such as sunshine hours, relative humidity, maximum and minimum temperatures, cloud covers and geographical location were employed by these authors for the development of their estimation formulae.

Angstrom (1924), Black.et.al (1954), Glover and McCulloch (1958) and Smith (1976) used sunshine hours to estimate the average solar radiation. Liu and Jordan (1960), Krieth (1962), Sharma and Pal (1965), and Whiller (1965) used declination angle and latitude in their formula. Many researchers have employed hours of bright sunshine to estimate solar radiation [3-4], [7-13]. Other workers e.g. Reddy, Glover and McCulloch derived their equations by using humidity, sunshine duration, relative humidity, temperature and latitude of the locations under study.

In this work, the estimation of monthly average daily global solar radiation on horizontal surface is made at Dhaka, employing the most common weather parameter, the sunshine hours available from NASA surface meteorology and solar energy: Inter-annual variability and Bangladesh Meteorology Department [5-6].

Firstly, the evaluation of Regression Coefficients ' $a$ ' and 'b' for Dhaka is made by using Angstrom method. The coefficients are then used to predict the monthly average daily global solar radiation. Secondly, a comparison of various correlations suggested to predict the insulation, is made, and the choice of best correlation is discussed.

\section{METHODOLOGY}

The extra terrestrial solar radiation on a horizontal surface $H_{0}$ is a function only of latitude and independent of other locational parameters. As the solar radiation passes through the earth's atmosphere, it is further modified by processes of scattering and absorption due to the presence of cloud and atmospheric particles. Hence, the daily global solar insulation incident on a horizontal surface $H$ is very much location specific and less than the extra terrestrial irradiation. 
The original Angstrom type regression equation related monthly average daily radiation to clear day radiation at the location and average fraction of possible sunshine hours

$$
\frac{\bar{H}}{\overline{H_{0}}}=a+b \frac{\bar{n}}{\bar{N}}
$$

Where,

$\bar{H}=$ monthly average daily radiation on a horizontal surface

$\bar{H}_{0}=$ Monthly average daily extraterrestrial radiation

$a, b=$ Empirical constants

$\bar{n}=$ Monthly average daily hours of bright sunshine

$\bar{N}=$ Monthly average of the maximum possible daily hours of sunshine or day length

The extra terrestrial solar radiation on a horizontal surface is calculated from the following equation [1]:

$$
\begin{aligned}
& H_{0}=\frac{24 \times 3600 \times I_{S C}}{\pi}(1 \\
& \left.+0.033 \cos \left(360 \frac{d}{365}\right)\right)
\end{aligned}
$$

Where,

$I_{s c}=1367 \mathrm{Wm}^{-2}$ is the solar constant and $H_{0}$ is in $\mathrm{Jm}^{-2}$

$d$ is day number, $\phi$ is the latitude of the location, $\delta$ is the declination angle given by

$$
\delta=23.45 \sin \left(360 \frac{284+d}{365}\right)
$$

and $\omega$ is the sunset hour angle given by

$$
\omega=\cos ^{-1}(-\tan \phi \tan \delta)
$$

The maximum possible sunshine duration $N$ is then given by

$$
N=\frac{2}{15} \omega
$$

In this paper $H_{0}$ and $N$ were computed for each month by using equations (2) and (5) respectively. The regression constants $a$ and $b$ in equation (1) have been calculated from the values of $\frac{\bar{H}}{\overline{H_{0}}}$ and $\frac{\bar{n}}{\bar{N}}$. The values of monthly average daily global radiation $H$ and the average number of hours of sunshine were obtained from daily measurements covering the period $1983-2010$ [5-6]. The method of least squares was used to obtain the constants $a$ and $b$ as follows:

$$
b=\frac{m \sum\left(\frac{n}{N}\right)\left(\frac{H}{H_{0}}\right)-\left(\sum\left(\frac{n}{N}\right)\right)\left(\sum\left(\frac{H}{H_{0}}\right)\right)}{m \sum\left(\frac{n}{N}\right)^{2}-\left(\sum\left(\frac{n}{N}\right)\right)^{2}}
$$

$$
a=\frac{\sum\left(\frac{H}{H_{0}}\right)}{m}-b \frac{\sum\left(\frac{n}{N}\right)}{m}
$$

To compute values of $\bar{H}_{e s t}$ (also known) as estimated $H$ the values of $a$ and $b$ were used in equation(1). The deviation between the estimated and measured values was determined using the following statistical parameters:

Mean Bias Error, MBE $=\frac{\sum\left(H_{\text {estimated }}-H_{\text {measured }}\right)}{m}$

Root Mean Square Error,

$$
\mathrm{RMSE}=\sqrt{\frac{\sum\left(H_{\text {estimated }}-H_{\text {measured }}\right)^{2}}{m}}
$$

Where, $m$ is the total number of observation points. The correalation coefficient $r$ between estimated and measured radiation values is

$$
r=\frac{\sum\left(H_{\text {estmated }}-\bar{H}_{e}\right)\left(H_{\text {measured }}-\bar{H}_{m}\right)}{\sqrt{\sum\left(H_{\text {estmated }}-\bar{H}_{e}\right)^{2} \sum\left(H_{\text {measured }}-\bar{H}_{m}\right)^{2}}}
$$

Where, $\bar{H}_{e}$ is the arithmetic mean value of the $m$ estimated values of the global solar radiation, $\bar{H}_{m}$ is the arithmetic mean value of the $m$ measured values.

The result of our model was compared with other previously stated models. The compared models are:

Reitveld's model [8]: an interesting correlation which is believed to be applicable anywhere in the world

$$
\frac{H}{H_{0}}=0.18+0.62 \frac{n}{N}
$$

Glover and McCulloch [10] (ibid): which relates a correlation model that takes into account the latitude effect as

$$
\frac{H}{H_{0}}=0.29 \cos \varphi+0.52\left(\frac{n}{N}\right)
$$

Fagbenle's model [11]:developed by Fagbenle which was believed to be suitable for the rain forst climatic zone as

$$
\frac{H}{H_{0}}=0.28+0.39 \frac{n}{N}
$$

Fre're's model [12]: this model is quoted by Nguyen as $\frac{H}{H_{0}}=a+b\left(\frac{n}{N}\right), a=-0.27+1.75\left(\frac{n}{N}\right)-1.34\left(\frac{n}{N}\right)^{2}, b=$ $1.32-2.90\left(\frac{n}{N}\right)+2.30\left(\frac{n}{N}\right)^{2}$ 
Turton's model [7]: which developed average regression constants for the humid tropical countries as

$$
\frac{H}{H_{0}}=0.30+0.40\left(\frac{n}{N}\right)
$$

Bahel et al model [9]: Bahel et al developed the model as

$$
\frac{H}{H_{0}}=0.16+0.87\left(\frac{n}{N}\right)+0.61\left(\frac{n}{N}\right)^{2}+0.349\left(\frac{n}{N}\right)^{3}
$$

Our model:

$$
\frac{H}{H_{0}}=0.23+0.57\left(\frac{n}{N}\right)
$$

The seven model listed above were applied to the sunshine data at Dhaka. The calculated and measured values of average daily global radiation on the horizontal surface were compared, to find the best correlation that will fit the measured global solar radiation.

\section{RESULTS AND DISCUSSION}

As can be seen in table 1, Reitvelt, Bahel et.el and our model has the best correlation coefficient while the lowest correlation coefficient is from Turton and fegbenle's model. The accuracy of each model used in the estimation of global solar radiation is tested by calculating the mean bias error (MBE \%) and the root mean square error (RMSE \%) respectively. It was observed that the lower the RMSE\%, the more accurate the equation used. Positive MBE\% shows over estimation and a negative $\mathrm{MBE} \%$ shows under estimation. So from the table 1 it is seen that though Bahel.et.al method has the highest correlation coefficient $(93 \%)$ but at the same time it has a serious RMSE (61\%) and also a major MBE (53\%). On the other hand, our model has the lowest over estimation (MBE $2.4 \%$ ). The RMSE\% values, which are a measure of the accuracy of estimation, have been found to be the minimum for our model (10.4) as shown in table 1. Standard Estimate error for our model is negligible and also the lowest among all

\begin{tabular}{|c|c|c|c|c|c|c|}
\hline MODEL & $\mathrm{a}$ & $\mathrm{b}$ & $\% \mathrm{MBE}$ & \%RMSE & $\mathrm{r}$ & SEE \\
\hline REITVELT & 0.18 & 0.62 & 5.62 & 10.6 & 0.89 & 1.94 \\
\hline GLOVER & 0.27 & 0.52 & 2.76 & 19.45 & 0.83 & 1.98 \\
\hline FEGBENLE & 0.28 & 0.39 & -7.56 & 12.52 & 0.76 & 2.3 \\
\hline TURTON & 0.3 & 0.4 & -2.64 & 10.97 & 0.75 & 2.01 \\
\hline FRE'RE & $\begin{array}{l}-0.27+1.75\left(\frac{n}{N}\right)- \\
1.34\left(\frac{n}{N}\right)^{2}\end{array}$ & $\begin{array}{l}1.32-2.90\left(\frac{n}{N}\right)+ \\
2.30\left(\frac{n}{N}\right)^{2}\end{array}$ & -3.86 & 10.62 & 0.8 & 1.95 \\
\hline $\begin{array}{c}\text { BAHEL ET } \\
\text { AL }\end{array}$ & \multicolumn{2}{|c|}{$0.16+0.87\left(\frac{n}{N}\right)+0.61\left(\frac{n}{N}\right)^{2}+0.349\left(\frac{n}{N}\right)^{3}$} & 52.68 & 61.07 & 0.93 & 11.2 \\
\hline OUR MODEL & 0.23 & 0.57 & 0.48 & 9.43 & 0.87 & 1.73 \\
\hline
\end{tabular}
models discussed here.

Table 1: Statistical test result of models applied for Dhaka

Table 2 shows the comparison between measured and estimated global solar radiation in Dhaka. As seen in table 2 the values of the clearness index $K_{T}$ for the atmosphere in Dhaka indicates poor sky condition in June-September where $\frac{n}{N}$ goes as low as 0.32 and $K_{T}$ values reach minimum, i.e. 0.38 (for July) and 0.40 (for August). This is due to the fact that June-September corresponds to the monsoon season in this part of the world, with less sunshine hours and heavy cloudy sky.

The monthly average daily global solar radiation estimated through the proposed model for Dhaka are given in table 3 along with the measured values and the estimated values from the other models. It is very encouraging to observe a very fine agreement between measured and estimated values obtained from our correlation.

In the present work, the low percentage error suggests that equation (6) can be used with confidence for Dhaka and also for other locations with similar climatologically conditions. This statement is also supported by the high value of correlation coefficient.

The distribution of average global solar radiation $\left(\mathrm{MJ} / \mathrm{m}^{2} /\right.$ day $)$ on a horizontal surface for different months in Dhaka, Bangladesh is shown in figure 1 while figure 2 shows 
the monthly average daily bright sunshine hours on horizontal surface.

Table 2: Monthly average data of solar radiation and relative daily brightness in Dhaka

\begin{tabular}{|c|c|c|c|c|c|c|c|}
\hline Month & $\begin{array}{c}\text { Day } \\
\text { length } \\
\mathrm{N}(\mathrm{hr})\end{array}$ & $\begin{array}{c}\text { Sunset } \\
\text { angle } \\
\omega_{s} \\
\text { degree }\end{array}$ & $\begin{array}{c}\text { Extra } \\
\text { terrestrial } \\
\text { radiation } \\
H_{0}\left(M J / m^{2}\right)\end{array}$ & $\begin{array}{c}\text { Radiation } \\
\text { measured } \\
H\left(M J / m^{2}\right)\end{array}$ & $\begin{array}{c}\text { Radiation } \\
\text { estimated }\end{array}$ & $\begin{array}{c}\text { Climate } \\
\text { index } \\
H\end{array}$ & $\begin{array}{c}\text { Relative } \\
\text { sun shine } \\
\text { hour( }\end{array}$ \\
\hline Jan & 10.71 & 80.34 & 25.16 & 15.69 & 12.964095 & 0.62 & 0.500467 \\
\hline Feb & 11.22 & 84.18 & 29.31 & 17.71 & 17.640858 & 0.6 & 0.652406 \\
\hline Mar & 11.86 & 88.95 & 34.06 & 20.12 & 19.587085 & 0.59 & 0.605396 \\
\hline Apr & 12.56 & 94.17 & 37.8 & 20.74 & 22.503339 & 0.55 & 0.640924 \\
\hline May & 13.15 & 98.60 & 39.71 & 19.08 & 21.319891 & 0.48 & 0.538403 \\
\hline Jun & 13.44 & 100.80 & 40.21 & 16.31 & 17.126947 & 0.41 & 0.34375 \\
\hline Jul & 13.31 & 99.81 & 39.78 & 15.19 & 16.372563 & 0.38 & 0.318557 \\
\hline Aug & 12.81 & 96.06 & 38.23 & 15.37 & 15.750402 & 0.4 & 0.319282 \\
\hline Sep & 12.13 & 90.97 & 35.14 & 14.51 & 14.918422 & 0.41 & 0.341303 \\
\hline Oct & 11.43 & 85.74 & 30.67 & 15.41 & 16.123887 & 0.5 & 0.51881 \\
\hline Nov & 10.85 & 81.35 & 26.14 & 15.45 & 15.583777 & 0.59 & 0.642396 \\
\hline Dec & 10.57 & 79.25 & 23.8 & 15.16 & 11.827046 & 0.64 & 0.468307 \\
\hline
\end{tabular}

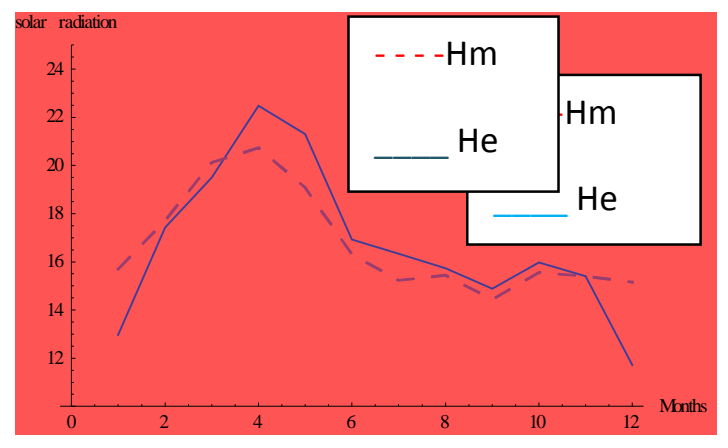

Fig 1: Monthly average daily global radiation in $\mathrm{MJ} / \mathrm{m}^{2}$ (1983-2010)

From figure 1 it is seen that maximum global solar radiation is received in the months of March, April or May (over $20 \mathrm{MJ} / \mathrm{m}^{2} /$ day).

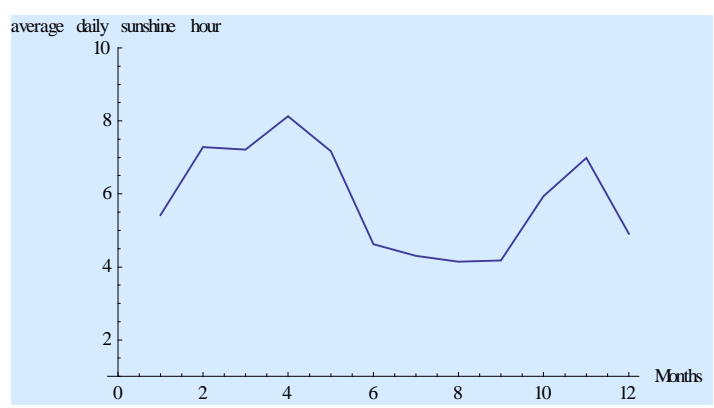

Fig 2: Monthly average daily bright sunshine hour

In monsoon and winter months the solar radiation receipt is lowest which is in the range of $14-15 \mathrm{MJ} / \mathrm{m}^{2} /$ day.

Table 3: Estimation of monthly average daily global solar radiation from various models for Dhaka

\begin{tabular}{|c|c|c|c|c|c|c|c|c|}
\hline Month & $H_{\text {measured }}$ & $\begin{array}{c}\text { Reitveld's } \\
\text { model }\end{array}$ & $\begin{array}{c}\text { McCulloch } \\
\text { model }\end{array}$ & $\begin{array}{c}\text { Fagbenle's } \\
\text { model }\end{array}$ & $\begin{array}{c}\text { Bahel et } \\
\text { al }\end{array}$ & $\begin{array}{c}\text { Turton's } \\
\text { mode }\end{array}$ & $\begin{array}{c}\text { Frere's } \\
\text { model }\end{array}$ & Our model \\
\hline Jan & 15.69 & 12.21 & 13.20 & 11.83 & 19.72 & 12.46 & 12.33 & 12.964095 \\
\hline Feb & 17.71 & 16.739 & 17.49 & 15.37 & 30.71 & 16.14 & 16.19 & 17.640858 \\
\hline Mar & 20.12 & 18.61 & 19.62 & 17.33 & 32.93 & 18.20 & 18.20 & 19.587085 \\
\hline Apr & 20.74 & 21.71 & 22.68 & 19.93 & 39.82 & 20.92 & 20.99 & 22.503339 \\
\hline May & 19.08 & 20.43 & 21.86 & 19.47 & 34.23 & 20.47 & 20.36 & 21.319891 \\
\hline Jun & 16.31 & 15.74 & 17.99 & 16.62 & 21.75 & 17.56 & 17.04 & 17.126947 \\
\hline Jul & 15.19 & 15.075 & 17.39 & 16.13 & 20.41 & 17.05 & 16.49 & 16.372563 \\
\hline Aug & 15.37 & 14.49 & 16.71 & 15.50 & 19.61 & 16.38 & 15.85 & 15.750402 \\
\hline
\end{tabular}




\begin{tabular}{|c|l|l|l|l|l|l|l|l|}
\hline Sep & 14.51 & 13.68 & 15.64 & 14.44 & 18.90 & 15.26 & 14.81 & 14.918422 \\
\hline Oct & 15.41 & 15.04 & 16.22 & 14.52 & 24.51 & 15.28 & 15.14 & 16.123887 \\
\hline Nov & 15.45 & 14.73 & 15.43 & 13.57 & 26.79 & 14.25 & 14.29 & 15.583777 \\
\hline Dec & 15.16 & 11.01 & 12.05 & 10.87 & 17.12 & 11.46 & 11.29 & 11.827046 \\
\hline
\end{tabular}

\section{REFERENCES}

[1]. J.A. Duffie and W.A. Beckman, Solar Engineering of thermal Processes, $2^{\text {nd }}$ edition, John Wiley, New York(1994). [2]. Shakir-ul Haque Khan, Towfiq-ur-rahaman, Shahadat Hossain, A brief study of the prospect of solar energy in generation of electricity in Bangladesh, June edition, 2012, Journal of selected areas in renewable and sustainable energy. [3] Firoz Ahmed, Empirical models for the correlation of monthly average daily global solar radiation with hours of sunshine on a horizontal surface at Karachi, Pakistan, Turk J Phys, 28 (2004), 301-307.

[4]. Louis E. Akpabio, Sunday E. Etuk, Relationship between global solar radiation and sunshine duration for Onne, Nigeria, Turk J Phys, 27 (2003), 161-167.

[5]. NASA surface meteorology and solar energy: Interannual variability

[6]. Bangladesh Meteorology Department.

[7]. S.M. Turton, the relationship between total irradiation and sunshine duration in the humid tropics, solar energy, 38,(1987),353-354.

[8]. M.R.Rietveld, A new method for estimating the regression coefficients in the formula relating solar radiation to sunshine agriculture meteorology, 19,(1978), 243-252.

[9]. Bahel.et.al., energy,12,(1987),131.

[10]. J.Glover and J.D.G. McCulloch, Q,J, Roy Met Soc.,84,(1958), 172.

[11]. L.E.Akpabio, comparison between solar radiation energy and the characteristic of wind power calculations in south eastern Nigeria, Nig. J. Phys., 4, (1992), 15-20.

[12]. B.T.Nguyen and T.L.Pryor, the relationship between global solar radiation and sunshine duration in Vietnam, Renewable energy,II,(1997), 47-60.

[13]. A. DeMiguel, J. Bilabo, S. Salson and A. Lage. Solar radiation and sunshine hour maps in castlla and Leon region(spain), renewable energy,4,(1994),933-940. 